\title{
Pulmonary metastases of the A549-derived lung adenocarcinoma tumors growing in nude mice. A multiple case study
}

\author{
Monika Jakubowska1凶, Martyna Śniegocka1', Ewa Podgórska1, Dominika Michalczyk-Wetula1, \\ Krystyna Urbanska1', Anna Susz'1,2, Leszek Fiedor'1, Janusz Pyka¹ and Przemysław M. Płonka1
}

'Faculty of Biochemistry, Biophysics and Biotechnology, Jagiellonian University, Kraków, Poland; ${ }^{2}$ Faculty of Chemistry, Jagiellonian University, Kraków, Poland

\begin{abstract}
Lung adenocarcinoma is a leading human malignancy with fatal prognosis. Ninety percent of the deaths, however, are caused by metastases. The model of subcutaneous tumor xenograft in nude mice was adopted to study the growth of control and photodynamically treated tumors derived from the human A549 lung adenocarcinoma cell line. As a side-result of the primary studies, observations on the metastasis of these tumors to the murine lungs were collected, and reported in the present paper. The metastasizing primary tumors were drained by a prominent number of lymphatic vessels. The metastatic tissue revealed the morphology of well-differentiated or trans-differentiated adenocarcinoma. Further histological and histochemical analyses demonstrated the presence of golden-brown granules in the metastatic tissue, similar to these found in the tumor tissue. In contrast to the primary tumors, the electron paramagnetic resonance spectroscopy revealed no nitric oxide hemoglobin complexes (a source of intense paramagnetic signals), in the metastases. No metastases were found in other murine organs; however, white infarctions were identified in a single liver. Taken together, the A549-derived tumors growing subcutaneously in nude mice can metastasize and grow on site in the pulmonary tissue. Thus, they can represent an alternative for the model of induced metastatic nodule formation, following intravenous administration of the cancerous cells.
\end{abstract}

Key words: adenocarcinoma, histological analysis, metastases, nude mice, photodynamic therapy, zinc pheophorbide $a$

Received: 25 May, 2013; accepted: 12 June, 2013; available on-line: 05 July, 2013

\section{INTRODUCTION}

Lung cancer is a leading cause of malignancy-related death worldwide (Goto et al., 2002; Oien et al., 2007; Wei et al., 2011). Development of this malignancy is correlated with, for example, exposure of the pulmonary tissue to carcinogens such as nitrosoamines and peroxides, mainly found in tobacco smoke or air pollution (Coussens and Werb, 2002; Wei et al., 2011). Advanced invasive lung cancer may spread from the primary tumor to other organs (Adiseshaiah et al., 2007). The typical sites of metastatic relapse of lung adenocarcinoma solid tumors are brain, bones, adrenal gland and liver (Nguyen et al., 2009). As much as $90 \%$ of deaths from lung cancer are due to metastases (Goto et al., 2002).
Photodynamic therapy (PDT), an efficient and noninvasive method of cancer treatment, has been approved for use in lung cancer patients (Moghissi, 2008). In this therapeutic approach, a light-inducible pro-drug (photosensitizer, PS) is injected into the patient circulation, and transported with blood to reach the cancerous tissue. Then, the malignant tissue is illuminated with light of an appropriate wavelength, either directly or by optical fibers. The photosensitizer becomes excited and reacts with molecular oxygen stored in the tissue, forming various toxic agents (Dougherty et al., 1998), mainly singlet oxygen, and other reactive oxygen and also probably nitrogen species (ROS, RNS, respectively). These reactive molecules cause destruction of neoplasia by (i) direct cell killing via e.g. apoptotic, necrotic or autophagic cell death, (ii) disruption of tumor vasculature, or (iii) activation of the immunological system against the tumor (Dougherty et al., 1998).

The generation of ROS and RNS, as reflected in oxygen consumption, may be monitored by the electron paramagnetic resonance (EPR) spectroscopy (Pogue et al., 2003). So far, this biophysical experimental approach has been applied to monitor the progress of PDT in the tumors in situ (Pogue et al., 2003; Krzykawska et al., 2012), but not to follow the effects of PDT in distant metastases of human cell line-derived tumors.

In this study, in which the primary A549-derived solid tumors growing in nude mice were subjected to PDT, the metastases were monitored and investigated by the means of histology and EPR spectroscopy. Zinc pheophorbide a (Zn-Pheide), a chlorophyll-derived photosensitizer, whose pharmacokinetics were found advantageous for PDT (Szczygiel et al., 2008), and which was shown to be effective against lung A549 adenocarcinoma tumors growing in $\mathrm{BABL} / \mathrm{cA}$ nude mice (Jakubowska et al., 2013a), was used. Also, a commercially available photosensitizer Photofrin ${ }^{\circledR}$, approved, for example, for the

\footnotetext{
e-mail: monika.jakubowska@uj.edu.pl
}

* Presented at 40th Jubilee Winter School of the Faculty of Biochemistry, Biophysics and Biotechnology of the Jagiellonian University "Contemporary insights into cancer. Risk, perspectives, expectations", February 16-21, 2013, Zakopane, Poland.

Abbreviations: Chl, chlorophyll $a$; Chlide, chlorophyllide $a$; DPPH, 1,1-diphenyl-2-picrylhydrazyl; EPR, electron paramagnetic resonance; FM, Fontana-Masson staining; $\mathrm{HbNO}$, nitrosylhemoglobin; $\mathrm{HE}$, hematoxylin and eosin staining: ip (iv), injection into peritoneum (vain); Iv, lymphatic vessels; MGG, May-Grünwald-Giemsa staining; PDT, photodynamic therapy; Ph, Photofrin ${ }^{\circledR}$; PPB, Pearls' Prussian blue staining; $P S$, photosensitizer; ROS (RNS), reactive oxygen (nitrogen) species; $s c$, subcutaneously; $T$, tumor; Zn-Pheide, zinc pheophorbide $a$. 
clinical therapy of lung cancer (Moghissi, 2008) was applied as a reference. The two PSs were compared in the context of their influence on the metastatic potential of the treated tumor.

\section{MATERIALS AND METHODS}

Materials. Animals. BALB/cA nude mice (C.Cg/AgBomTac-Foxn1 ${ }^{\text {nu}}$ N20; male, 5-6-week old animals) were purchased from Taconic (Bomholtvej, Denmark). The mice were maintained under sterile conditions in a ventilated cabin equipped with HEPA filters, in a $12 \mathrm{~h}$ light cycle, with a free access to water and a sterile laboratory rodent chow M-Z provided by Ssniff (Soest, Germany).

Photosensitizers. Zinc pheophorbide $a$ was prepared from chlorophyll a (Chl) according to the previously described methods (Fiedor et al., 1992; Szczygieł et al., 2008; Jakubowska et al., 2013a). Chl was isolated from Spirulina laporte, then treated with a plant enzyme, chlorophyllase (EC No. 3.1.1.14), to obtain water-soluble chlorophyllide a (Chlide). Chlide was demetalated using glacial acetic acid, and then metalated with zinc(II) acetate. After purification, $\mathrm{Zn}$-Pheide was stored dried at $-30^{\circ} \mathrm{C}$ under Ar atmosphere.

Photofrin ${ }^{\mathbb{B}}$ was a generous gift of Dr hab. Dominika Nowis (Department of Immunology, Medical University of Warsaw, Poland).

Chemicals, cell culture media, and drugs: Accustain $^{\circledR}$ May-Grünwald stain, 1,1-diphenyl-2-picrylhydrazyl (DPPH), DMEM high glucose, eosin Y, Giemsa stain and trypsin were purchased from Sigma-Aldrich (St. Louis, USA); acetone, acetic acid, ethanol, formaldehyde, glycerol, hydrochloric acid, methanol, neutral red, potassium hexacyanidoferrate(II), silver nitrate, sodium thiosulfate and xylene from POCh (Gliwice, Poland); ammonia from Eurochem (Tarnów, Poland); Consul Mount and paraffin from Thermo (Waltham, USA); fetal calf serum (FCS) from Gibco (Grand Island, USA); Mayer's hematoxylin from Aqua-Med (Łódź, Poland); ketamine (Bioketan) and xylazine (Sedazin) from Vetoquinol Biowet (Puławy, Poland); penicillin and streptomycin from Polfa Tarchomin (Warsaw, Poland); Photofrin $^{\circledR}$ from QLT PhotoTherapeutics, Inc. (Vancouver, Canada); Polysine ${ }^{\circledR}$ Glass Slides from Gerhard Menzel GmbH (Brunswick, Germany).

Equipment and software. A ventilated cabin equipped with HEPA filters was obtained from Tecniplast (Buguggiate, Italy); a centrifuge EBA 21 from Hettich-Zentrifugen (Tuttlingen, Germany); a $655 \mathrm{~nm}$ diode laser from Eurotek (Warsaw, Poland); an embedding center TEC-2800 and Cryo Console TEC-2800 from Histo-Line Laboratories (Milan, Italy); a Finesse 325 manual microtome from Thermo (Waltham, USA); a Nikon Eclipse Ti light microscope and a D80 digital camera from Nikon (Tokyo, Japan); a digital video camera SSC-DC54AP from Sony (Tokyo, Japan); an EPR X-band (ca. 9.4 GHz) EMX spectrometer from Bruker BioSpin GmbH (Rheinstetten, Germany), and the WinEPR program was supplied by the manufacturer; Eleana 0.9.8 software was kindly provided by Dr Marcin Sarewicz, (Department of Molecular Biophysics, the Jagiellonian University, Kraków, Poland; http://www.wbbib. uj.edu.pl/web/gbm/eleana).

Methods. Tumor model. All animal experiments were approved by the Local Ethical Committee for Animal Experimentation in Krakow (approval No. 14/2011).

The human lung A549 adenocarcinoma cells (Giard et al., 1973), originally gifted to our laboratory by Dr hab.
Jolanta Saczko (Wrocław Medical University, Wrocław, Poland), were cultivated in vitro under standard conditions $\left(37^{\circ} \mathrm{C}, 5 \% \mathrm{CO}_{2}\right.$ in a humid atmosphere). The cells were cultured in DMEM high glucose medium supplemented with heat-inactivated FCS $(10 \%, v / v)$ and antibiotics (penicillin and streptomycin). The A549 cells were trypsinized, centrifuged $(1400 \mathrm{rpm}, 4 \mathrm{~min})$, washed in PBS twice, and injected $s c\left(1 \times 10^{6}, 100 \mu \mathrm{l}\right.$ of PBS $)$ into the left flanks of the 7-8-week old mice (the animals were acclimatized for two weeks before experiments). In total, 106 mice were injected with the A549 cells. The tumors were measured every 7 days, and the general condition and weight of the animals (see Table S1 in the Supplementary Materials on web site: www.actabp.pl) were monitored as well.

Three perpendicular diameters $a, b$ and $c$, measured using calipers, allowed us to calculate the mean diameter and volume of tumors, according to the formulas $3 \sqrt{a \times b \times c}($ Schreck, 1936) and $(\pi / 6) \times a \times b \times c$ (Feldman $e t$ al., 2009), respectively.

Photodynamic therapy. The photodynamic therapy protocols using $\mathrm{Zn}$-Pheide as a photosensitizer, varying either in PS dose (1-10 mg/kg) or ways of PS administration (ip and iv), were tested previously (Jakubowska $e t$ al., 2013a). For all these experiments, the animal lungs, livers and lymph nodes (lymphonodus axillaris accessories and lymphonodus subiliacus) were harvested, and inspected carefully for the presence of macroscopically visible metastases of the A459 adenocarcinoma tumors. Also, the tumor tissues were harvested and analyzed (see in Jakubowska et al., 2013a).

In the study of metastases to the animal lungs, animals $(n=34)$ bearing the A549 tumors of the mean diameter of $6 \mathrm{~mm}$ were randomized, and then the tumors were treated with $\mathrm{Zn}$-Pheide only $(\mathrm{n}=4)$, light only $(\mathrm{n}=4)$, PS and light (Zn-Pheide or Photofrin ${ }^{\circledR}, \mathrm{n}=13$ or $\mathrm{n}=5$, respectively). The injections of PS or placebo were given to the tail vain.

The histological analysis was performed for a single A549 tumor containing golden-brown granules, subjected to photodynamic treatment with $\mathrm{Zn}$-Pheide (ip injection, PDT 20). The studies of anatomic pathology in livers revealed morphological changes in a single organ harvested from the mouse bearing the A549 tumor of the mean diameter of $4 \mathrm{~mm}$ treated with $\mathrm{Zn}$-Pheide (ip injection, PDT 30) and light. Eight untreated animals served as controls.

The PS solutions were prepared immediately before iv $\left(1 \mathrm{mg} / \mathrm{kg}, \sim 200 \mu \mathrm{l}, \mathrm{Zn}\right.$-Pheide or Photofrin $\left.{ }^{\circledR}\right)$ or ip (10 mg/kg, $500 \mu \mathrm{l}$, Zn-Pheide) administration, and were obtained by dissolving $\mathrm{Zn}$-Pheide or Photofrin ${ }^{\circledR}$ in a small volume of EtOH and aqua pro injectione containing PBS $(9: 1 ; i v$ administration), or Zn-Pheide in a small volume of $\mathrm{EtOH}$ and PBS (ip administration). The final concentrations of $\mathrm{EtOH}$ in solutions were $5 \%$ and $10 \%$, respectively.

For PDT of the tumors, Zn-Pheide solutions were administered iv 70 or $140 \mathrm{~min}$ before illumination (referred to as PDT 70 and PDT 140, respectively), or ip 20 or 30 min before illumination (PDT 20 and PDT 30, respectively), and Photofrin ${ }^{\circledR}$ solutions were administered iv 24 $\mathrm{h}$ before illumination (PDT Ph). After administration of PS or placebo, the tumors were exposed for $20 \mathrm{~min}$ to monochromatic red light $(655 \mathrm{~nm})$ at the fluency of 100 $\mathrm{mW} / \mathrm{cm}^{2}$. The total light dose delivered to the tumors was equal to $120 \mathrm{~J} / \mathrm{cm}^{2}$. Before illumination, the animals were anesthetized (ketamine and xylazine, $8 \mathrm{mg} / \mathrm{kg}$ and $30 \mathrm{mg} / \mathrm{kg}$, respectively, ip injection) and their bodies were protected from light, leaving only the tumor sur- 
face exposed. The growth of tumors was monitored for up to 120 days after the treatment in animals which followed the PDT 70, PDT 140, PDT Ph protocols, and in the control group, or monitored for up to 100 days after the treatment in animals that followed the PDT 20 and PDT 30 protocols.

Biological material. The animals were anesthetized (ketamine and xylazine, $150 \mathrm{mg} / \mathrm{kg}$ and $10 \mathrm{mg} / \mathrm{kg}$, respectively, ip injection), and then their blood was taken from the ventricles of beating heart. The animal organs were collected, photographed, weighted (for lung mass see Table S1 in the Supplementary Materials at www. actabp.pl), and fixed using a 5\% buffered formaldehyde solution for histological and histochemical analyses, or frozen in liquid nitrogen for EPR measurements (see below).

Histology and histochemistry. The fixed (5\% formaldehyde, $\mathrm{pH}$ 7.4) lung, liver and tumor tissues were dehydrated $(50 \%, 75 \%, 96 \%$ and $99.8 \%$ aqueous $\mathrm{EtOH}$, and xylene), and then paraffin-embedded. The tissue slices $(5 \mu \mathrm{m}$, prepared after freezing on the cooling platform, or incubating in icy cold water) were mounted on Polysine ${ }^{\circledR}$ glass slides. The sections were pre-incubated in xylene $(\times 2)$, then in $99.8 \%(\times 2), 96 \%, 80 \%, 70 \%$, $50 \%$ aqueous $\mathrm{EtOH}$, and distilled water, and stained according to modified HE (hematoxylin and eosin), MGG (May-Grünwald-Giemsa), or FM (Fontana-Masson) and PPB (Pearl's Prussian blue) protocols (Zawistowski, 1983).

Hematoxylin and eosin staining. The tissue sections were incubated in Mayer's hematoxylin (12 min), rinsed with tap water $(15 \mathrm{~min})$, and stained in $0.1 \%$ eosin Y solution (1.5 min; $96 \%$ EtOH and distilled water, $7: 3)$. After the staining the sections were incubated in $70 \%, 96 \%(\times 2), 99.8 \%(\times 2)$ aqueous $\mathrm{EtOH}$, then in $\mathrm{xy}-$ lene $(\times 2)$, sealed in Consul Mount, and covered.

May-Grünwald-Giemsa staining. The sections of lungs were incubated in Accustain ${ }^{\circledR}$ May-Grünwald stain solution at $37^{\circ} \mathrm{C}\left(20 \mathrm{~min}\right.$; stock Accustain ${ }^{\circledR}$ MayGrünwald stain solution and distilled water, 3:32), dried with paper tissue, protected from light and incubated in Giemsa stain solution at $37^{\circ} \mathrm{C}(40 \mathrm{~min} ; 0.5 \%$ Giemsa stock in glycerol and methanol, 1:3, and distilled water, $1: 400)$. Afterwards, the sections were immersed quickly in $0.15 \%$ aqueous acetic acid, rinsed with distilled water, dried, dehydrated (99.8\% EtOH and acetone; 1:1), and finally incubated in xylene and sealed as described above.

Fontana-Masson staining. The sections of lungs containing golden-brown granules were protected from light, whereupon incubated in ammoniacal silver nitrate solution (according to Bielechowsky's method, after Zawistowski (1983)) at $56^{\circ} \mathrm{C}$ (40 $\left.\mathrm{min}\right)$; the negative control sections were incubated in distilled water. The sections were next rinsed with distilled water, and incubated in $5 \%$ aqueous sodium thiosulfate (3 $\mathrm{min})$, rinsed with tap water $(3 \mathrm{~min})$, stained in $0.5 \%$ aqueous neutral red (5 $\mathrm{min})$, rinsed with tap water (3 min), dehydrated in $70 \%, 96 \%(\times 2), 99.8 \%(\times 2)$ aqueous $\mathrm{EtOH}$, and then in xylene $(\times 2)$, and sealed as described above.

Pearls' Prussian blue staining. All procedures were performed using glass equipment only. The sections of lungs were washed in distilled water (15 min), and incubated in fresh mixture of $2 \%$ potassium hexacyanidoferrate(II) and 1\% hydrochloric acid aqueous solutions $(1: 1 ; 30 \mathrm{~min})$. Then the sections were washed in distilled water, stained in $0.1 \%$ eosin Y (1.5 min; $96 \%$ EtOH and distilled water, $7: 3)$, washed in distilled water, stained in $0.5 \%$ aqueous neutral red $(5 \mathrm{~min})$, and rinsed with tap water $(3 \mathrm{~min})$. Then the sections were washed in $70 \%, 96 \%(\times 2), 99.8 \%(\times 2)$ aqueous $\mathrm{EtOH}$, and in xylene $(\times 2)$, and sealed as described above.

Analysis. The tissue slides were inspected under a light microscope (40 and $100 \times$ ), to distinguish between the normal tissues, metastases, and other anatomic pathologies. The sections of lungs and tumors were photographed and analyzed using the Nis elements F 3.0 software supplied by the manufacturer of the microscope, and the liver sections using a digital video camera and the MultiScanBase software supplied by CSS (Warsaw, Poland).

Professor Andrzej Słomiński (Health Science Center, the University of Tennessee, Memphis, Tennessee), is gratefully acknowledged for expert analysis of the sections, and the discussion.

EPR measurements. The samples for EPR measurements (the right lungs, and the left merge of lobus hepatis sinister lateralis of the liver) were frozen in liquid nitrogen in standard $2 \mathrm{~cm}$ long glass tubes (inner diameter $0.4 \mathrm{~cm}$ ) directly after excision and were stored at $-80^{\circ} \mathrm{C}$ till the measurements. The statistics of the lung samples are given in Table S1 in the Supplementary Materials at www.actabp.pl.

The lung samples were measured at $77 \mathrm{~K}$ in a quartz Dewar container using an EPR X-band (ca. 9.4 GHz) EMX spectrometer, applying the following parameters: field $3340 \pm 150 \mathrm{Gs}$, modulation amplitude 5 Gs, conversion time $40.96 \mathrm{~ms}$, time constant $20.48 \mathrm{~ms}$, microwave power $4.2 \mathrm{~mW}$, receiver gain $2 \times 10^{4}$, and resolution 1024 points. For each spectrum 16 scans were accumulated. The liver samples were recorded using a different set of parameters: field $3280 \pm 250 \mathrm{Gs}$, conversion time $163.40 \mathrm{~ms}$, time constant $81.92 \mathrm{~ms}$, a single scan recorded for each spectrum. The standard solutions of chemically pure nitrosylhemoglobin ( $\mathrm{HbNO}$ ) were synthesized as described in Plonka et al., 1999, and the samples were recorded using the parameters as for the lung samples, apart from field $3331 \pm 250 \mathrm{Gs}$ and receiver gain $1 \times 10^{4}$. The spectra were analyzed using the WinEPR and Eleana 0.9.8 software. The peak-to-peak amplitudes of the semiquinone free-radical signals were compared for either lungs or livers (normal organ $v s$ organ with anatomic pathology). All the spectroscopic data were normalized to the constant mass of the tissue and to the instrumental gain. Mr Piotr Lacki is gratefully acknowledged for recording and analysis of the liver spectra.

Statistical analysis. The results were expressed as the mean values of three to eight animals/samples \pm S.D. The statistical significance of differences between the mean values were tested using the parametric Student's $t$ test, proceeded with ANOVA. The $p$ values $<0.05$ were considered statistically significant.

\section{RESULTS AND DISCUSSION}

\section{Tumors and metastases}

89 out of $106 \mathrm{BALB} / \mathrm{cA}$ nude mice (84\%) which received the sc injection of the human lung A549 adenocarcinoma cells at number of $1 \times 10^{6}$ bore the A549derived tumors. The solid tumors were palpable within 3-7 weeks after the implantation, in line with our earlier reports (Jakubowska et al., 2013a). Initially, the tumors (Fig. 1A; T - tumor) were identified as objects of the diameter of a sand grain growing under the skin. During the period of growth in the animal hosts, the tumors were easily distinguishable from the murine tissues (e.g. 


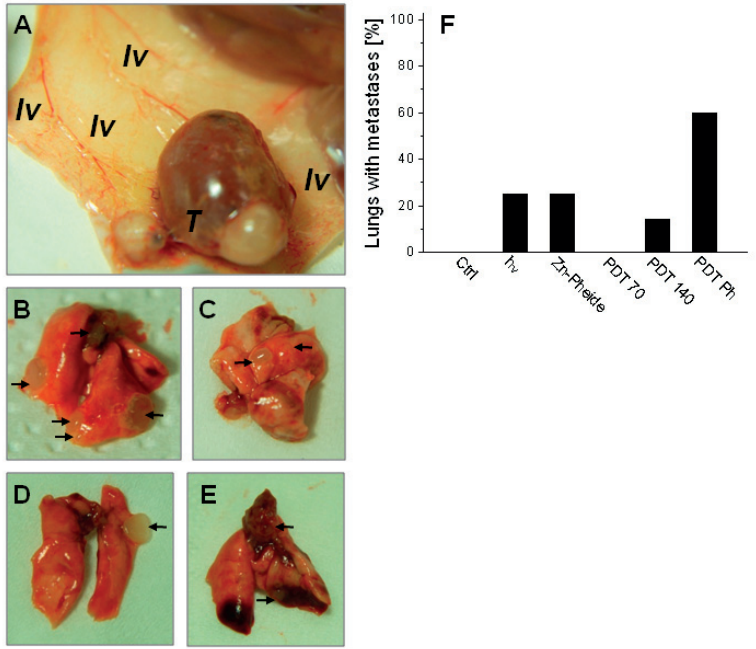

Figure 1. Metastases of the lung A549 adenocarcinoma tumors to murine lungs.

(A) Metastatic lung A549 adenocarcinoma tumor (mean diameter $19.8 \mathrm{~mm}$ ) growing in BALB/CA nude mouse. For pulmonary metastases of the tumor see Fig. $\mathbf{1} \mathbf{E} ; l v-$ the lymphatic vessels originating from the tumor, $T$ - the tumor. (B) Lungs harvested from a mouse treated with Zn-Pheide and light (PDT 140). (C) Lungs harvested from a mouse treated with light only (hv). (D, E) Lungs harvested from mice treated with Photofrin ${ }^{\oplus}$ and light (PDT Ph). (F) Percentage of the lungs with A549 tumor metastases in untreated control (Ctrl), light only (hv) or Zn-Pheide only (ZnPheide) treated control, Zn-Pheide and light treated (PDT 70 and PDT 140), and Photofrin ${ }^{\circledast}$ and light treated (PDT Ph) animals. The results are represented as means.

from muscles or adipose tissue) under both macroscopic and histological examinations (not shown).

Metastases of the A549 tumors to the lungs were found in $7 \%$ (six out of 89 ) of murine hosts. A characteristic feature of these tumors was the presence of well developed lymphatic vessels (lv) surrounding the primary tumor (Fig. 1A). The metastases to the lungs had the form of numerous pale secondary tumors growing on the surface of the lung lobes and inside the pulmonary parenchyma (Fig. 1B-E). No metastases were found in the lungs of untreated control animals (Fig. 1F), but they were present in the lungs of light-alone (25\%; Fig. 1C, F) and Zn-Pheide-alone (25\%, Fig. 1F) treated control animals, and in the lungs of the animals undergoing photodynamic therapy: in a single animal treated with PDT 140 (14\%; Fig. 1B, F) and three mice treated with PDT Ph $(60 \%$; Fig. 1D-F). The statistical analysis revealed that the percentage of pulmonary metastases (Fig. $1 \mathrm{~F})$ was significantly increased in the lungs of the animals that received PDT Ph in comparison to the lungs of untreated control animals $(p<0.01)$, and the lungs of the animals treated with PDT $70(p<0.02)$. No significant differences $(p>0.05)$ were found between light-alone treated and photodynamically treated (PDT 70, PDT 140 or PDT Ph) tumors.

Although the growth of tumors undergoing PDT Ph was inhibited in comparison to untreated control tumors (not shown), the therapeutic protocol using $1 \mathrm{mg} / \mathrm{kg}$ of Photofrin ${ }^{\circledR}$ and $655 \mathrm{~nm}$ red light cannot be considered as being safe for the treated animals due to the appearance of numerous metastases in lungs causing a high risk of severe respiratory problems (Douillard et al., 2013). Such dose of the drug is reported as "low" (Peng et al., 2001) in comparison with the clinically approved dose of $2 \mathrm{mg} / \mathrm{kg}$ in PDT of lung cancer (Moghissi, 2008).
Also, the $655 \mathrm{~nm}$ wavelength light is optimal to excite Zn-Pheide (Jakubowska et al., 2013a), but not Photofrin ${ }^{\circledR}$ whose absorption maximum is located at $630 \mathrm{~nm}$ (Detty et al., 2004).

The presence of tumor metastases in animals undergoing photodynamic therapy depends not only on the chemical nature of the applied photosensitizer or the spectral characteristics of light, but also on the tumor model, and the interaction between the tumor and its animal host (Schreiber et al., 2002). In this context, PDT was reported to have a dual role in metastatic processes. Momma et al. (1998) observed a significant increase in number of pulmonary metastases of rat prostate cancer growing in rat hosts, treated photodynamically with Verteporfin as a photosensitizer. On the other hand, a significant decrease in the number of metastases to the lungs and lymph nodes was reported for rat glioma xenografts growing in male nude mice undergoing PDT with Pd-Bacteriopheophorbide a (Schreiber et al., 2002), and rat mammary tumors growing in rat females undergoing PDT with indocyanine green (Chen et al., 1999). A good photosensitizer should not only destroy the primary tumor subjected to the photodynamic treatment, but also prevent metastasis, e.g. by activation of the immunological system to eradicate the secondary tumors.

Neither the presence of (metastatic) tumors, nor the experimental procedures affected the animal weight (Fig. S1A and Table S1 in the Supplementary Materials at www.actabp.pl) and general health status, despite the fact that the mass of lungs with metastases increased by $25-50 \%$ (Fig. S1B and Table S1 in the Supplementary Materials at www.actabp.pl).

\section{Histological and histochemical analyses of the pulmonary metastases}

The metastatic potential of human lung tumors is investigated in vivo in immunodeficient animals, e.g. in an orthotopic ("on site", in the animal lungs) model of tumor growth and spontaneous formation of the metastases (Chen et al., 2005), or after injection of cancerous cells to the tail vain, leading to the formation of nodules in the lungs of the host (Goto et al., 2002; Adiseshaiah

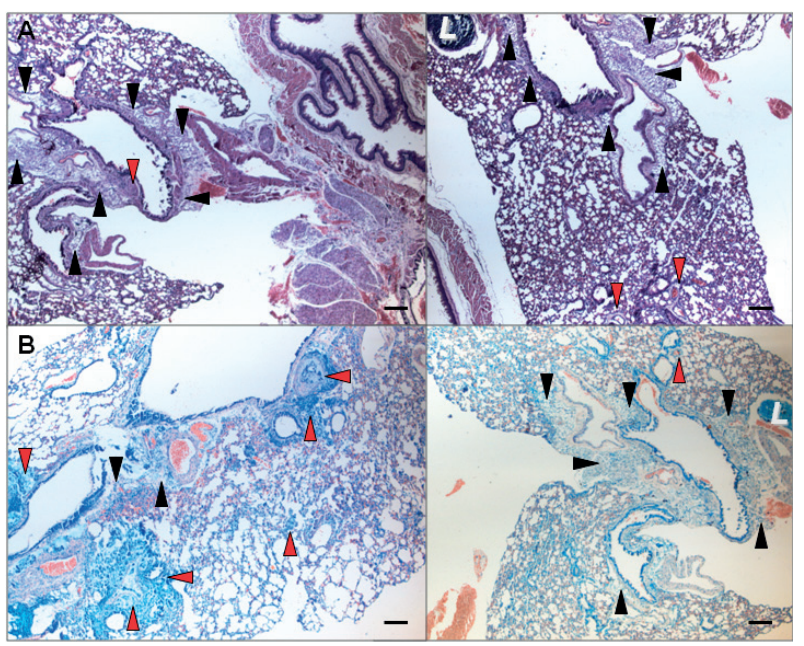

Figure 2. Histological sections of murine lung with metastases of the lung A549 adenocarcinoma tumors, magnification 40x, scale bar $100 \mu \mathrm{m}$

The lung harvested from a mouse treated with Photofrin and light (PDT Ph). Triangles indicate the metastatic adenocarcinoma tissue of glandular (red) or signet ring (black) morphology, $L-$ the lymph nodes (right panel). (A) Hematoxylin and eosin staining of the lung. (B) May-Grünwald-Giemsa staining of the lung. 


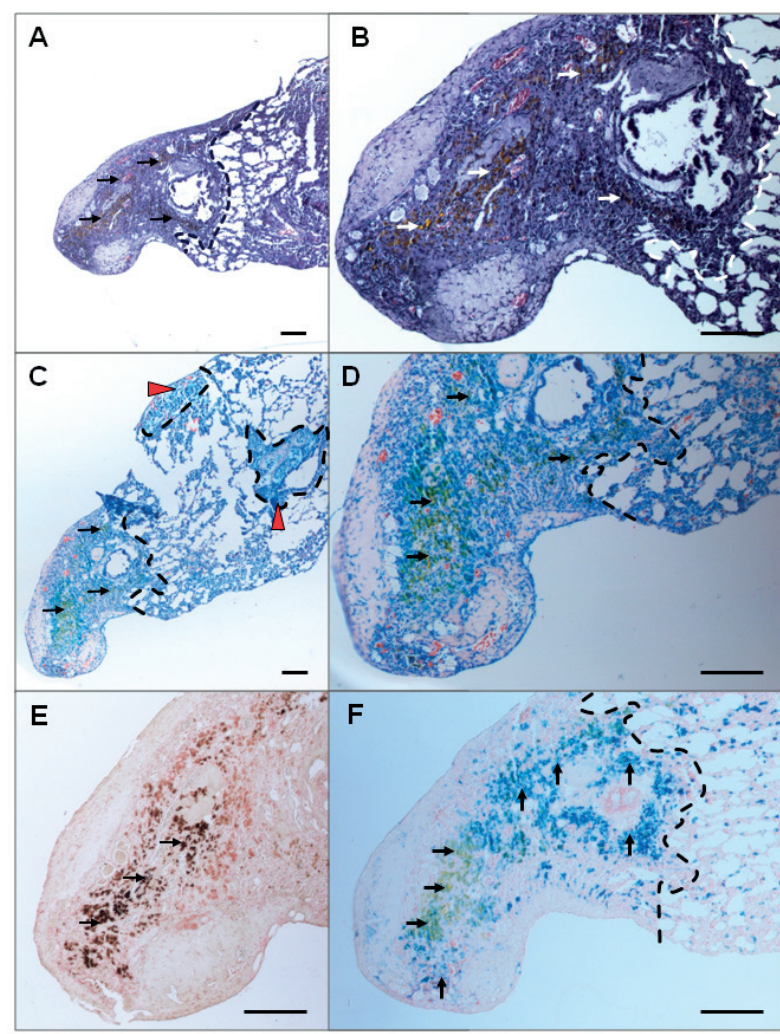

Figure 3. Histological sections of the murine lung with a metastasis of the lung A549 adenocarcinoma tumor growing on the periphery of the lung, magnification $40 \times$, scale bar $100 \mu \mathrm{m}$ (A and C), and 100x, scale bar $100 \mu \mathrm{m}$ (B, D-F).

The lung harvested from a mouse treated with light only (hv). The dashed line indicates a border between the metastatic and the normal lung tissues, the horizontal arrows indicate Prussian bluenegative and the vertical arrows indicate Prussian blue-positive granules in the metastatic tissue. (A, B) Hematoxylin and eosin staining of the lung. (C, D) May-Grünwald-Giemsa staining of the lung. (E) Fontana-Masson staining of the lung. (F) Pearls' Prussian blue staining of the lung.

et al., 2007; Wei et al., 2011; Gutshner et al., 2013). In the present work a spontaneous formation of pulmonary metastases of the human-derived lung A549 adenocarcinoma tumor growing sc in $\mathrm{BALB} / \mathrm{cA}$ nude mice, is described.

The paraffin-embedded sections of secondary A549 tumors growing inside the lung parenchyma (Fig. 2) and on the surface of lung lobes (Fig. 3) were analyzed using $\mathrm{HE}$ (Fig. 2A and Fig. 3A, B) and MGG (Fig. 2B and Fig. 3C, D) histological staining, and FM (Fig. 3E, for the negative control see Fig. S3 in the Supplementary Materials) and PPB (Fig. 3F) histochemical staining. The metastatic adenocarcinoma tissue growing inside the parenchyma of lung differed markedly from normal alveolar pulmonary tissue, and revealed a biphasic growth of this cancerous tissue. Both the areas of glandular morphology (Fig. 2 and Fig. 3C, red triangles), characteristic for well differentiated adenocarcinoma (Oien et al., 2007), and the areas of signet-ring morphology of trans-differentiated adenocarcinoma (Fig. 2, black triangles), were observed.

The analysis of the metastases growing on the surface of the lung lobe (Fig. 3, and Fig. S3 in the Supplementary Materials) showed the presence of golden-brown granules spreading through the cancerous tissue. Similar granules were found inside the solid adenocarcinoma tumor tissue (Fig. S2 in the Supplementary Materials).
The human lung malignancies containing melanin have already been reported by Enochs et al. (1993).

The tissue sections indentified to contain goldenbrown granules were subjected to histochemical analysis for argyrophil (capable of impregnation with silver(I) ions, dark brown or black color after the staining) or Prussian blue positive (containing iron(III) ions deposits, blue or purple color after the staining) properties.

To assess the capability of impregnation with silver, Fontana-Masson staining (Fig. 3E, and Fig. S3 in the Supplementary Materials) procedures were used (Fontana, 1912; Masson, 1914). This histochemical staining method facilitates detection of pigments, such as melanin (Slominski et al., 1994) or lipofuscin (Double et al., 2008), which is also called "aging pigment". The Pearls' Prussian blue staining (Fig. 3F) allows for visualization of hemosiderin (van Deursen et al., 1989), an iron-storage complex present mainly in tissues undergoing various inflammatory processes. Hemosiderin is usually formed after release of iron from the destroyed red blood cells in the presence of macrophages. Both those histochemical reactions were positive, proving the presence of argyrophil (Fig. 3E) and hemisiderin (Fig. 3F) granules, but the areas of specific staining did not fully overlap (Fig. 3F).

\section{Anatomic pathologies in murine liver}

The metastases to liver were reported for numerous tumors growing sc in the animal hosts (Kozlowski et al., 1984; Fidler, 1986; Fidler et al., 1990). For this reason the livers harvested from murine hosts of the lung A549 adenocarcinoma tumors were carefully inspected. Easily distinguishable areas of white tissue were found in a single liver, spreading on the liver surface (Fig. 4A). The enlargement of both the spleen and the surrounding lymph nodes indicated activation of the immunological system, possibly due to the process of metastasizing to liver. However, the histological analysis of the liver tissue section did not reveal the presence of human cancerous cells; instead, white infarctions were observed in the liver parenchyma (Fig. 4B). Numerous young neutrophils infiltrated the infarctions and the border between the normal and necrotic liver tissues. This phenomenon, though observed in a single animal, is relevant to metastasis because it may be the remnant of pre-existing metastases, or just be a symptom of a general poor condition of the tumor-bearing animal.

\section{EPR analysis}

The representative EPR spectra of normal and pathological (metastases or white infarctions) lung and liver

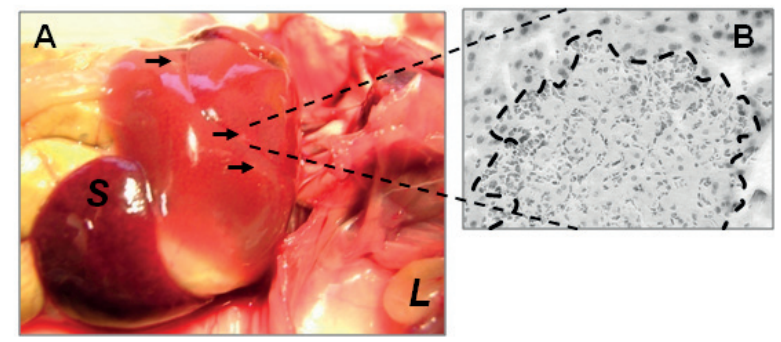

Figure 4. An example of non-metastatic anatomic pathology in the murine liver harvested from an animal subjected to PDT 30. (A) Areas of necrotic tissue (white infarctions) on the liver surface. Arrows indicate the infarctions, the dashed line indicates a border between the normal and necrotic liver tissues, $S-$ the enlarged spleen, $L-$ the enlarged lymph node. (B) White infarction in the liver tissue, hematoxylin and eosin staining. 


\section{A}
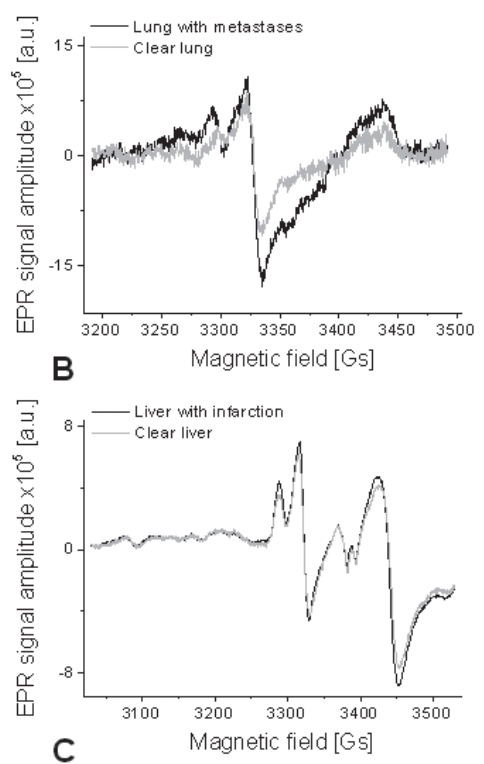

C

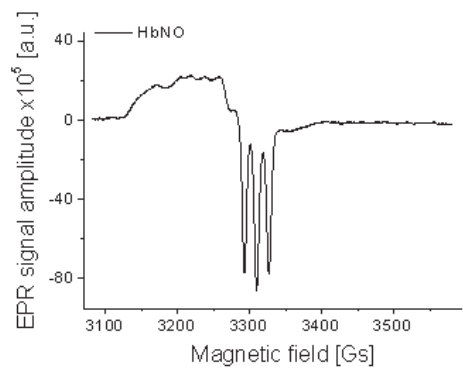

Figure 5. EPR spectra of normal murine organs (light grey) and organs with pathologies (black).

(A) Representative spectra of normal murine lung and lung with metastases. (B) A representative spectrum of normal murine liver and the spectrum of liver with necrosis (white infarctions). (C) A representative spectrum of chemically pure nitrosylhemoglobin (black), a positive control for the lung and liver spectra.

tissues are shown in Fig. 5. The intense free radical singlet signals of g 2.004 (Chamulitrat et al., 1995; Elas et al., 2008) were detected for lung and liver samples, no matter whether normal or with metastases, or infarctions. The mean values of the amplitudes of the free radical EPR signals detected ex vivo in normal lung tissue (20 samples in total) and in the lung tissue containing the A549 tumor metastases (six samples) were not significantly different (not shown). For the normalized EPR free radical signal amplitudes and numeric data see Fig. S1C and Table S1 in the Supplementary Materials at www.actabp.pl.

In the lung tissue with metastases, the free radical signal tended to be weaker than in the control (Table S1 in the Supplementary Material at www.actabp.pl). Therefore, even the putative presence of melanin, as suggested by FM staining of the lungs (Fig. 3E), did not contribute measurably to the signal. The lung malignancy reported by Enochs et al. (1993) was suspected to be a melanoma metastasis, because of the presence of pheomelanin revealed by means of the EPR spectroscopy. In general, "melanotic melanomas" are considered being strongly melanotic tumors, whereas the amount of pigment in the metastasis of the A549 adenocarcinoma reported hereby was clearly low. Nevertheless it is intriguing, as the primary tumor was amelanotic. Possibly, melanization of the pulmonary tumors of various origins, including the secondary tumors, might be related to a high partial pressure of oxygen in the lungs. As ectopic melanization may be an additional feature of oxidative stress, which promote the progression of metastasis (Slominski et al., 1998), this observation may deserve a special attention and further systematic studies.

The high intensity of free radical signals detected in the samples might originate from the significant metabolic ratio of both organs, but the paramagnetic nature of the signal is probably different. In the lungs, involved in the processes of respiration, the presence of free radicals might be associated with, for example, the continuous exposure to oxygen and air pollution (Ohta et al., 1985), and may lead to mutations and development of lung cancer (Wei et al., 2011). In the liver tissue, the EPR free radical signals originate from semiquinones involved in cellular respiration (Elas et al., 2008).

Nitrosylhemoglobin (Fig. 5C), a paramagnetic complex of hemoglobin and NO, can be detected by means of the EPR spectroscopy in tissues undergoing various inflammatory processes associated with tumor growth (Emanuel et al., 1969) and necrotization (Maruyama et al., 1971). It may also be generated as a result of the response of the tissue to endotoxemic stress (Płonka et al., 1999). We detected intense HbNO EPR signals in situ in the lung A549 adenocarcinoma tumors growing in nude mice hosts, either control or photodynamically stressed using red light and Zn-Pheide as a photosensitizer (Jakubowska et al., 2013b). Moreover, the intensities of the respectable signals varied significantly. As in the latter work we detected for the first time the HbNO EPR signals in the human-derived tumors growing $s c$ in nude mice, it was of a great importance to find out whether metastases of those tumors were a source of the EPR HbNO signals, carrying the message that the NO-generating cells became activated. However, no $\mathrm{HbNO}$ signals were found in the samples of the murine pulmonary tissue with metastases (compare Fig. 5A and C). This may be due to the strongly oxidizing milieu of the lung, transforming NO to EPR-silent nitrate(III) and (V) (Plonka et al., 2003). Another possible background of this effect may be a different physiology of the NOgenerating cells, most probably alveolar macrophages, neutrophils, and pulmonary endothelium (Chlopicki et al., 1999), as compared to the ones infiltrating the primary tumors. Furthermore, the NO-generating cells in metastases are generally less active than these of the primary tumors (Haque et al., 2011). The mediatory role of Tcells between the primary tumor cells, and the metastasizing tumor cells must be excluded in the model of human-derived tumor growing in nude mouse.

Other components of the EPR spectra might originate from transition metal ions present in the tissue: manganese(II) ions in the lung spectra $\left(\mathrm{g} \sim 2.002, \mathrm{~A}_{\mathrm{SNS}}\right.$ ca. $90 \mathrm{Gs}$, reported by Yonetani et al. (1970) and Reed and Cohn (1973)), reduced iron-sulfur proteins in the lung and liver spectra ( $\mathrm{g} \sim 1.93$, reported by Chamulitrat et al. (1995), and Elas et al. (2008)), and molybdenum(V) ions in the liver spectra $(g \sim 1.97$, reported by Chamulitrat et al. (1995)).

In general, EPR measurements did not reveal any significant difference between normal, and metastasesinvaded organs. Comparing this result with the observations on the primary tumors (Jakubowska et al., $2013 \mathrm{~b}$ ) one has to conclude, that the primary tumor affects various mechanisms leading to the generation of paramagnetic species, mainly free radicals, more strongly than the secondary tumors. This is an important point concerning not only the biology of adeno- 
carcinomas, but possibly also the mechanisms and effectiveness of PDT.

\section{CONCLUSIONS}

The human lung A549 adenocarcinoma cells showed metastatic potential after sc inoculation to the flanks of $\mathrm{BALB} / \mathrm{cA}$ nude mice. The secondary pulmonary tumors appeared in $7 \%$ of the lungs of animals undergoing different treatments, and were growing as well differentiated or trans-differentiated adenocarcinomas. The metastases were not found in other murine organs or lymph nodes. The EPR spectroscopy revealed intense free radical singlet signals in both lung and liver tissue samples, and the signal intensity was not affected by anatomic pathologies occurring in the tissues. These findings open an interesting direction for further investigation of novel in vivo models of human-derived tumor metastasis.

\section{Acknowledgements}

We are grateful to the Reviewers for the inspiring discussion and thorough correction of the paper.

This research was supported in part by grants from the Polish Ministry of Science and Higher Education (R05 04303 to KU, and N N405 051940 to AS), the National Science Center ( $N$ N405 050540 to KU) and the Foundation for Polish Science (TEAM/2010-5/3 to LF). The Faculty of Biochemistry, Biophysics and Biotechnology of the Jagiellonian University is a beneficiary of structural funds from the European Union (grant No: POIG.02.01.00-12-064/08 - Molecular biotechnology for health).

\section{REFERENCES}

Adiseshaiah P, Lindner DJ, Kalvakolanu DV, Reddy SP (2007) FRA-1 Proto-oncogene induces lung epithelial cell invasion and anchorageindependent growth in vitro, but is insufficient to promote tumor growth in vivo. Cancer Res 67: 6204-6211.

Chamulitrat W, Jordan S, Mason R, Litton A, Wilson J, Wood E, Wolberg G, Molina y Veida L (1995) Targets of nitric oxide in a mouse of liver inflammation by Corynebacterium parvum. Arch Biochem Biophys 316: $30-37$.

Chen WR, Zhu W-G, Dynlacht JR, Liu H, Nordquist RE (1999) Longterm tumor resistance induced by laser photo-immunotherapy. Int $J$ Cancer 81: 808-812.

Chen JJW, Lin Y-C, Yao P-L, Yuan A, Chen H-Y, Shun C-T, Tsai M-F, Chen C-H, Yang P-C (2005) Tumor-associated macrophages: the double-edged sword in cancer progression. J Clin Oncol 23: 953964.

Chlopicki S, Bartuś JB, Gryglewski RJ (1999) Biphasic response to lipopolysaccharide from $E$. coli in the isolated ventilated blood-perfused rat lung. J Physiol Pharmacol 50: 551-565.

Coussens LM, Werb Z (2002) Inflammation and cancer. Nature 420: $860-867$.

Detty MR, Gibson SL, Wagner SJ (2004) Current clinical and preclinical photosensitizers for use in photodynamic therapy. $J \mathrm{Med}$ Chem 47: 3897-3915.

Double KL, Dedov VN, Fedorow H, Kettle E, Halliday GM, Garner B, Brunk TU (2008) The comparative biology of neuromelanin and lipofuscin in the human brain. Cell Mol Life Sci 65: 1669-1682.

Dougherty TJ, Gomer CJ, Henderson BW, Jori G, Kessel D, Korbelik M, Moan J, Peng, Q (1998) Photodynamic therapy. I Natl Cancer Inst 90: 889-905.

Douillard S, Rozec B, Bigot E, Aillet L, Patrice T (2013) Secondary reactive oxygen species production after PDT during pulmonary tumor growth in sera of nude mice. Photodiagn Photodyn Ther 10: 62-71.

Elas M, Bielanska J, Pustelny K, Plonka P, Drelicharz L, Skorka T, Tyrankiewicz U, Wozniak M, Heinze-Paluchowska S, Walski M, Wojnar L, Fortin D, Ventura-Clapier R, Chlopicki S (2008) Detection of mitochondrial dysfunction by EPR technique in mouse model of dilated cardiomyopathy. Free Radic Biol Med 5: 321-328.

Emanuel NM, Saprin AN, Shabalkin VA, Kozlova LE, Krugljakova KE (1969) Detection and investigation of a new type of ESR signal characteristic of some tumour tissues. Nature 222: 165-167.
Enochs WS, Nilges MJ, Swartz HM (1993) A standardized test for identification and characterization of melanins using electron paramagnetic resonance (EPR) spectroscopy. Pigmented Cell Res 6: 91-99.

Feldman JP, Goldwasser R, Mark S, Schwartz J, Orion I (2009) A mathematical model for tumor volume evaluation using two-dimensions. J Appl Quant Methods 4: 455-462.

Fidler IJ (1986) Rationale and methods for the use of nude mice to study the biology and therapy of human cancer metastasis. Cancer Metast Rev 5: 29-49.

Fidler IJ, Naito S, Pathak S (1990) Orthotopic implantation is essential for the selection, growth and metastasis of human real cell cancer in nude mice. Cancer Metast Rev 9: 149-165.

Fiedor L, Rosenbach-Belkin V, Scherz A (1992) The stereospecific interaction between chlorophylls and chlorophyllase. possible implication for chlorophyll biosynthesis and degradation. J Biol Chem 267: 22043-22047.

Fontana A (1912) Verfahren zur intensiver und raschen Farbung des Treponema pallidum und anderer Spirochäten. Dermatol Wochenschr 55: 1003-1004 (in German).

Giard DJ, Aaronson SA, Todaro GJ, Arnstein P, Kersey JH, Dosik H, Parks WP (1973) In vitro cultivation of human tumors: establishment of cell lines derived from a series of solid tumors. I Natl Cancer Inst 51: 1417-1423.

Goto H, Yano S, Zhang H, Matsumori Y, Ogawa H, Blakey DC, Sone S (2002) Activity of a new vascular targeting agent, ZD6126, in pulmonary metastases by human lung adenocarcinoma in nude mice. Cancer Res 62: 3711-3715.

Gutschner T, Hämmerle M, Eißmann M, Hsu J, Kim Y, Hung G, Revenko A, Arun G, Stentrup M, Groß M, Zörnig M, MacLeod AR, Spector DL, Diederichs S (2013) The noncoding RNA MALAT1 is a critical regulator of the metastasis phenotype of lung cancer cells. Cancer Res 73: 1180-1189.

Haque A, Noman AS, Koide N, Odkhuu E, Naiki Y, Hashimoto S, Komatsu T, Yoshida T, Yokochi T (2011) An ADP ribosylation factor-GTPase activating protein negatively regulates the production of proinflammatory mediators in response to lipopolysaccharide. Cancer Immunol Immunother 60: 1439-1446.

Jakubowska M, Szczygiel M, Michalczyk-Wetula D, Susz A, Stochel G, Elas M, Fiedor L, Urbanska K (2013a) Zinc-pheophorbide $a$ - highly efficient low-cost photosensitizer against human adenocarcinoma in cellular and animal models. Photodiagn Photodyn Ther 10: 266-277.

Jakubowska M, Michalczyk-Wetula D, Pyka J, Susi A, Urbanska K, Płonka BK, Kuleta P, Lacki P, Krzykawska-Serda M, Fiedor L, Płonka PM (2013b) Nitrosylhemoglobin in photodynamically stressed human tumors growing in nude mice. Nitric Oxide, in press, DOI: 10.1016/j.niox.2013.08.004.

Kozlowski JM, Fidler IJ, Campbell D, Xu Z-I, Kaighn ME, Hart IR (1984) Metastatic behavior of human tumor cell lines grown in the nude mouse. Cancer Res 44: 3522-3529.

Krzykawska M, Dabrowski JM, Szczygiel M, Stochel G, Arnaut LG, Pereira MM, Urbanska K, Elas M (2012) Non-invasive prognostic tools for phototherapeutic response in murine tumors. Eur J Cancer 48 (Suppl 5): S193.

Maruyama T, Kataoka N, Nagase S, Nakada H, Sato H, Sasaki H (1971) Identification of three-line electron spin resonance signal and its relationship to ascites tumors. Cancer Res 31: 179-184.

Masson P (1914) La grande endocrine de l'intestin chez l'homme. Les Comptes Rendus de l'Académie des sciences (Paris) 138: 59-61 (in French).

Moghissi K (2008) Role of Photodynamic Therapy (PDT) in Lung Cancer. In Advances in Photodynamic Therapy. Basic, Translational, and Clinical, Hamblin MR, Mróz P, eds, pp 443-459. Artech House: Boston|London.

Momma T, Hamblin MR, Wu HC, Hasan T (1998) Photodynamic therapy of orthotopic prostate cancer with benzoporphyrin derivative: local control and distant metastasis. Cancer Res 58: 5425-5431.

Nguyen DX, Bos PD, Massagué J (2009) Metastasis: from dissemination to organ-specific colonization. Nat Rev Cancer 9: 274-285.

Ohta Y, Shiraishi H, Tabata Y (1985) An electron spin resonance study of free radicals in black dust deposited in human lungs. Arch Environ Health 40: 279-282.

Oien KA, Stewart I, Jefrey Evans TR (2007). Unknown Primary. In The Cancer Handbook, Alison MR, ed, vol. 1, pp. 852-865. John Wiley \& Sons Ltd.: The Atrium, Southern Gate, Chichester.

Peng Q, Warloe T, Moan J, Godal A, Apricena F, Giercksky K-E, Nesland JM (2001) Antitumor effect of 5-aminolevulinic acid-mediated photodynamic therapy can be enhanced by the use of a low dose of Photofrin in human. Cancer Res 61: 5824-5832.

Plonka PM, Chlopicki S, Plonka BK, Jawien J, Gryglewski RJ (1999) Endotoxaemia in rats: detection of nitrosyl-haemoglobin in blood and lung by EPR. Curr Top Biophys 23: 47-53.

Plonka PM, Wisniewska M, Chlopicki S, Elas M, Rosen GM (2003) Xband and S-band EPR detection of nitric oxide in murine endotoxaemia using spin trapping by ferro-di( $N$-(dithio-carboxy)sarcosine). Acta Biochim Pol 50: 799-806. 
Pogue BW, O'Hara JA, Demidenko E, Wilmot CM, Goodwin IA, Chen B, Swartz HM, Hasan T (2003) Photodynamic therapy with verteporfin in the radiation-induced fibrosarcoma-1 tumor causes enhanced radiation sensitivity. Cancer Res 63: 1025-1033.

Reed GH and Cohn M (1973) Electron paramagnetic resonance studies of manganese(II)-pyruvate kinase-substrate complexes. I Biol Chem 248: 6436-6442.

Schreck R (1936) Further quantitative methods for the study of transplantable tumors. The growth of R39 sarcoma and Brown-Pearce carcinomas. Am J Cancer 28: 345-363.

Schreiber S, Gross S, Brandis A, Harmelin A, Rosenbach-Belkin V, Scherz A, Salomon Y (2002) Local photodynamic therapy (PDT) of rat C6 glioma xenografts with Pd-bacteriopheophorbide leads to decreased metastases and increase of animal cure compared with surgery. Int J Cancer 99: 279-285.

Slominski A, Paus R, Plonka P, Chakraborty A, Maurer M, Pruski D, Lukiewicz S (1994) Melanogenesis during the anagen-catagen-telogen transformation of the murine hair cycle. I Invest Dermatol 102: 862-869.

Slominski A, Paus R, Mihm MC (1998) Inhibition of melanogenesis as an adjuvant strategy in the treatment of melanotic melanomas: selective review and hypothesis. Anticancer Res 18: 3709-3716.
Szczygieł M, Urbanska K, Jurecka P, Stawowska I, Stochel G, Fiedor L (2008) Central metal determines pharmacokinetics of chlorophyllderived xenobiotics. J Med Chem 51: 4412-4418.

van Deursen CTBM, van Dieijen-Visser MP, Koudstaal J, Brombacher PJ (1989) Determination of tissue iron and ferritin in liver pathology comparison of histochemical and biochemical results. J Clin Chem Clin Biochem 27: 345-349.

Wei Q, Jiang H, Xiao Z, Baker A, Young MR, Veenstra TD, Colburn NH (2011) Sulfiredoxin-peroxiredoxin IV axis promotes human lung cancer progression through modulation of specific phosphokinase signaling. Proc Natl Acad Sci USA 108: 7004-7009.

Yonetani T, Drott HR, Leigh JS, Reed GH, Waterman MR, Asakura $\mathrm{T}$ (1970) Electromagnetic properties of hemoproteins. III Electron paramagnetic resonance characteristics of iron(III) and manganese(II) protoporphyrins IX and their apohemoprotein complexes in high spin states. J Biol Chem 245: 2998-3003.

Zawistowski S (1983) Histological Technique, Histology and the Principles of Histopathology. PZWL, Warsaw (in Polish). 